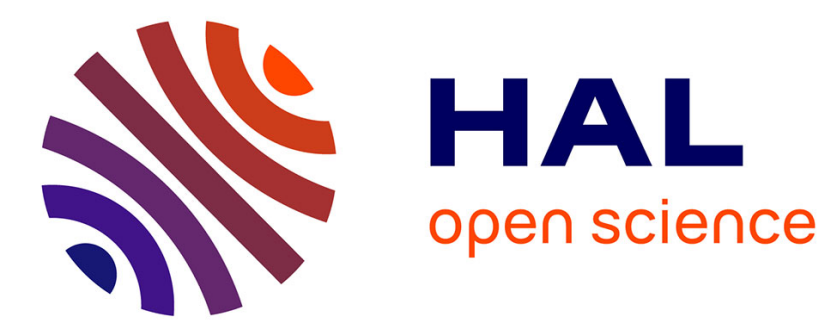

\title{
Recycled concrete aggregate attrition during mixing new concrete
}

\author{
Jaime Moreno Juez, Bogdan Cazacliu, Alexis Cothenet, Riccardo Artoni, \\ Nicolas Roquet
}

\section{- To cite this version:}

Jaime Moreno Juez, Bogdan Cazacliu, Alexis Cothenet, Riccardo Artoni, Nicolas Roquet. Recycled concrete aggregate attrition during mixing new concrete. Construction and Building Materials, 2016, 116, pp.299-309. 10.1016/j.conbuildmat.2016.04.131 . hal-01522629

\section{HAL Id: hal-01522629 \\ https://hal.science/hal-01522629}

Submitted on 15 May 2017

HAL is a multi-disciplinary open access archive for the deposit and dissemination of scientific research documents, whether they are published or not. The documents may come from teaching and research institutions in France or abroad, or from public or private research centers.
L'archive ouverte pluridisciplinaire HAL, est destinée au dépôt et à la diffusion de documents scientifiques de niveau recherche, publiés ou non, émanant des établissements d'enseignement et de recherche français ou étrangers, des laboratoires publics ou privés. 


\title{
Recycled concrete aggregate attrition during mixing new concrete
}

\author{
J.Moreno Juez, B. Cazacliu*, A. Cothenet, R. Artoni, N. Roquet \\ IFSTTAR, Aggregates and Material Processing Laboratory, Route de Bouaye - CS4, 44344 \\ Bouguenais Cedex, Nantes, France \\ *Corresponding author. bogdan.cazacliu@ifsttar.fr
}

\begin{abstract}
In this work, the recycled concrete aggregate (RCA) friability during mixing was studied in order to better understand the evolution of this material during the mixing process and improve the recycled aggregate concrete mix-design. The influence of some important materials and process parameters was evaluated: initial abrasion resistance and initial moisture of the aggregates, mixer geometry, mixing time and mixing speed. To assess the mixing process effect on the recycled concrete aggregate friability, three different aspects were evaluated; the mass loss (mass of fraction inferior to $2.5 \mathrm{~mm}$ ) the grading and the angularity evolutions with mixing time of an initially 10-14 mm aggregate. Tests were carried out in two types of laboratory concrete mixers, a planetary 30 liters mixer from Skako and an intensive 5 liters Erich mixer. The results revealed that in normal laboratory setting of the mixers configuration, the mass loss for natural aggregate (NA) is less than $1 \%$ of the coarse aggregate. This percentage reach 3\% for good quality recycled concrete aggregate (MDE value of 21 ) and 5\% for lower quality recycled concrete aggregate (MDE value of 27). The mass loss directly depends on the mixing parameters and the degradation of the recycled concrete aggregate drastically increased when the mixing speed was raised to 500 RPM. By analyzing the grading evolution during mixing, it was shown that both cleavage (creation of intermediate size particles) and attrition (creation of small particles) mechanisms influenced the aggregate degradation. However, the configuration of mixing significantly influenced the proportion of attrition and cleavage mechanisms. To complete this work, the angularity evolution showed that recycled concrete aggregate surface becomes smoother and the edges more rounded after mixing.
\end{abstract}

\section{Keywords}

Recycled concrete aggregates; Friability; Concrete mixing; PSD evolution

\section{Introduction}

Recycled concrete aggregates (RCA) are widely used in road constructions, but a possibility that deserves to be more exploited is certainly their reuse as a substitute for natural aggregate (NA) in concrete. This practice is often hampered by the lack of technical confidence in the practical use. It is largely recognized that the high porosity of the hardened cement mortar attached to the RCA particles [1] alters aggregate water absorption and density [2,3,4], and it could have adverse effects on the performance of the second generation of concrete. Some authors have determined the residual mortar content (RMC) in RCA using different techniques. Using a heat treatment method, Sánchez de Juan 
[5] determined that the RMC varies from 33 to 55\% for 4/8mm RCA and from 23 to $44 \%$ for $8 / 16 \mathrm{~mm}$ RCA. Abbas [6] obtained that $20 \%$ of the $4.75 / 9.5 \mathrm{~mm}$ fraction particles are constituted between 95 and $100 \%$ of residual mortar and more than $50 \%$ of the particles in $4.75 / 19 \mathrm{~mm}$ fraction are constituted by less than $15 \%$ of the residual mortar. Hua Duan [4] also quantified the RMC depending on different sources and preparation methods. He observed that the RMC varies between 14 and 63\% for a 5/10mm aggregate and between 24 and $61 \%$ for a $10 / 20 \mathrm{~mm}$. Belin et al. [7] showed a decrease of RMC with the water to cement ratio of the parent concrete. In his study, Gonçalves [8] summarized the different specifications regarding RCA composition of the main consuming countries.

Several researchers have shown that the RCA are more sensitive to fragmentation than the natural aggregates. For instance, Barbudo [9] observed a typical ratio of 2 between the Los Angeles' values of RCA and natural aggregates. Zega et al., [10] showed similar results and demonstrated the influence of the abrasion characteristics of the original natural aggregates: the lesser the abrasion loss of the original natural aggregate, the higher the increase of the abrasion loss in the subsequent RCA. They also showed an increase of the Los Angeles value with the RMC. Also, Dao et al. [11] showed that the Micro-Deval (MDE) value of the RCA is related to the compressive strength of original concrete and to the MDE of the original aggregate, but their study showed that most generally the Micro-Deval value of the RCA is significantly higher than the MDE of the original aggregate. In addition, it has to be noted that the RMC depends on the history of recycling of RCA, i.e. the crushing sequences [12]. Moreover, the kinetics of fracture depends on the degree of liberation of the RCA particles [13]. As a consequence, the sensitivity of RCA to experimental manipulations is much higher than for natural aggregates. Schouenborg et al. [14] illustrated the increase of amount of material passing the $8 \mathrm{~mm}$ sieve with the energy of sieving RCA. Also, for a mechanical sieving during 10 minutes, the amount of passing was $7.9 \%$ for a RCA obtained from a 26.5 MPa concrete, $9.5 \%$ for a RCA obtained from a $41 \mathrm{MPa}$ concrete and only $0.2 \%$ for a natural aggregate. Quattrone et al. [15] shown that the mass of the recycled aggregates decreases when toweling to obtain the saturated surface dry state, during the standard water absorption test procedure.

During industrial processing particles can suffer different breakage mechanisms [16]. Breakage can arise from a number of interactions, including particle impacts onto walls and solid objects in motion such as hammers or blades, or collisions between particles in free space. A granulometric evolution of aggregates under prolonged mixing was observed by González Ortega et al. [17] for concrete produced with barite aggregate which is a natural aggregate characterized by a low resistance. The authors measured the grading before and after the mixing and observed a higher amount of fine particles for aggregates with lower resistance to fragmentation (Los Angeles value of 20 for the reference natural aggregate vs 40 for barite). The increase of the finer particles content was greater for initially moistened barite aggregate. The authors highlighted the high amount of particles below 0.125 mm created.

The operation of mixing the constituents of concrete yields stresses which are expected to produce the separation of the attached mortar from the original natural aggregate and alter the original size and angularity of the RCA. While the effect of the RMC on the increase in water absorption capacity of RCA is largely considered in designing new generation of concrete, the importance of breakage during the mixing process of the degraded RCA abrasion/fragmentation characteristics compared with natural aggregates has not so far been analyzed in detail for RCA. However, combined with the higher porosity and its larger variability, the generation of fine particles during mixing could contribute to explain the difficulty to control the slump and workability loss when producing recycled aggregate concrete $[18,19]$. 
The objective of this paper is to provide information on the RCA friability during mixing, in order to improve the control of the mixing process and the design of recycled aggregate concrete. Tests were performed at laboratory scale. The influence of significant materials and process parameters is evaluated: residual mortar content and initial moisture of the aggregates, mixer geometry, mixing time and mixing speed. The mixing process effect is assessed throughout the mass loss, the grading and angularity evolutions of coarse natural aggregates and RCA.

\section{Experimental method}

\subsection{Materials and mix-design}

Tests were carried out on a concrete mixture composed of 10/14 aggregate, natural 0/2.5 silicocalcareous sand from Pilier, France, cement CEMI 52.5 from Lafarge Ciments (St Pierre La Cour, France). The most significant physical properties of the materials employed are presented in Table1 (more detailed properties in Annex A). In all tests, the cement content was $350 \mathrm{~kg} / \mathrm{m}^{3}$, the sand to gravel ratio was 1.0 and the water to cement ratio 0.59 . The water dosage was chosen to obtain an initial slump (NF EN 12350-2) [20] between 100 and $150 \mathrm{~mm}$ when fixing a mixing time of $300 \mathrm{~s}$ (maximum mixing time employed) and using natural coarse aggregates.

The tests compare the behavior of three types of 10/14 coarse aggregates: natural gneiss aggregates from Pontreaux (France) and two RCA differentiated by the Micro-Deval abrasion value (MDE, NF EN 1097-1) [21]. The RCA used in this study are commercially produced by the "Gonesse Recycling Centre" located in France; these aggregates are composed of 99\% recycled concrete and 1\% of inert materials.

The higher MDE value RCA are obtained by sorting by density the main RCA feed (the material provided by the recycling plant), using a laboratory water jigging technique [22]. The jig box was filled with RCA and once the separation process completed, the material located in the upper third of the container was recovered and used for the tests. The material recovered has then a lower density and a lower abrasion resistance than the initial RCA material introduced; the material of the bottom is discarded.

The abrasion resistance of the aggregates was determined by the Micro Deval test, following the French standards (NF EN 1097-1) [21]. The natural coarse aggregate had a MDE value of 6 (MDE-6), the RCA directly provided by the recycling plant had a MDE value of 21 (MDE-21) and the less dense RCA had a MDE value of 27 (MDE-27).

To perform the different tests, materials were used in Air Dry (“AD”) state or in a Saturated Surface Dry ("SSD”) state. To obtain the SSD aggregate, the RCA were immersed in water during 72 hours and drained 2 hours before the mixing test.

Table 1.

Physical properties of coarse aggregates.

\begin{tabular}{|c|c|c|c|c|c|c|}
\hline Aggregate Type & Origin & $\begin{array}{c}\text { Size } \\
(\mathrm{mm})\end{array}$ & $\begin{array}{c}\text { Los Angeles } \\
(\%)\end{array}$ & $\begin{array}{c}\text { Micro Deval } \\
(\%)\end{array}$ & $\begin{array}{c}\text { Density } \\
\left(\mathrm{kg} / \mathrm{m}^{3}\right)\end{array}$ & $\begin{array}{c}\text { Water absorption } \\
(\%)\end{array}$ \\
\hline $\begin{array}{c}\text { Recycled concrete } \\
\text { aggregate (RCA) }\end{array}$ & $\begin{array}{c}\text { Gonesse } \\
\text { (France) }\end{array}$ & $10-14$ & 32 & 21 & 2260 & 5,6 \\
\hline $\begin{array}{c}\text { Recycled concrete } \\
\text { aggregate (RCA) }\end{array}$ & $\begin{array}{c}\text { Gonesse } \\
\text { (France) }\end{array}$ & $10-14$ & 35 & 27 & 2159 & 7,0 \\
\hline Natural (NA) & $\begin{array}{c}\text { Pontreau } \\
\mathrm{x}\end{array}$ & $10-14$ & 15 & 6 & 2636 & 0,3 \\
\hline
\end{tabular}




\begin{tabular}{|l|l|l|l|l|l|l|}
\hline & (France) & & & & & \\
\hline
\end{tabular}

\subsection{Equipment}

\subsubsection{Mixers}

The tests were conducted in two laboratory pan mixers (Figure 1): a planetary 30 liters mixer from Skako and a 5 liters Erich mixer. Both mixers have one agitator and one scraper. In the planetary mixing system a one blade agitator rotates with a nominal speed of 97 rotations per minute (RPM) around an axis turning, together with the scraper, at a nominal speed of 36 RPM. In this kind of mixer the vessel is fixed, the scraper has a circular movement and the blade a planetary movement as shown in figure 1a. The Eirich mixer has inclined rotating vessel which typically runs between 45 and 90 RPM, whereas the agitator can have rotation speeds between 50 and 700 RPM. We can have for this kind of mixer two different configurations depending on the sense of the vessel and agitator rotation; a co-current configuration (figure 1b) where the vessel and agitator rotate in the same direction and a counter-current configuration (figure 1c) where the vessel and agitator rotate in opposite direction. We have to note that the vessel always rotates in the clockwise direction.

In this study, all tests were carried out with the nominal configuration of the Skako mixer. The Eirich mixer was set in co-current and in counter current configurations with mixing speeds of 150, 300 and 500 RPM. The vessel turned at 45 RPM in all cases. The volume of the batches was 11 liters for the Skako mixer and 4.5 liters for the Eirich mixer. These volumes were chosen as they represent a compromise between the mixers capacity and the amount of material to be analyzed.

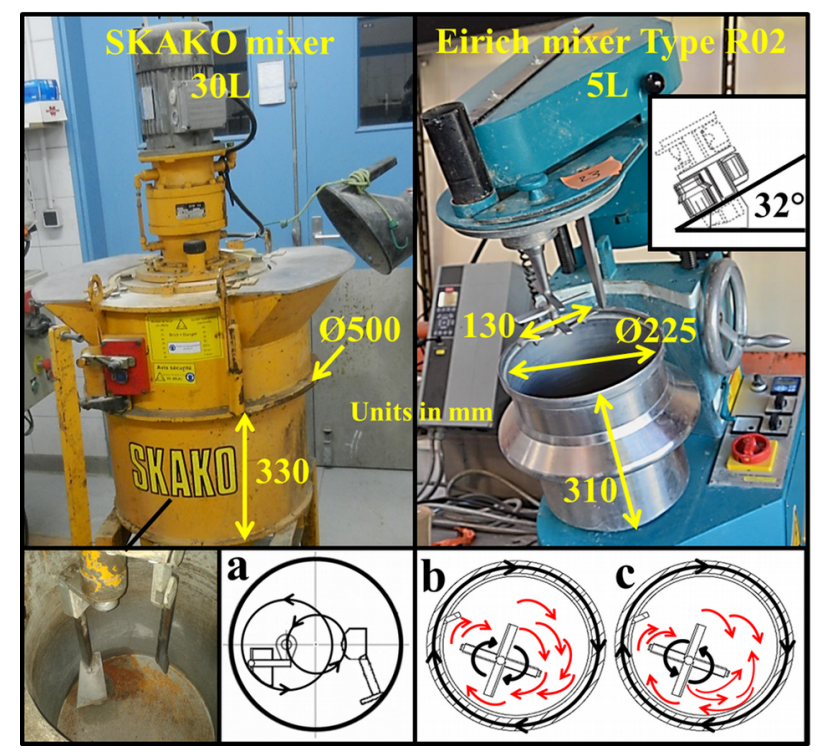

Figure 1. Laboratory mixers: Skako (left) with a planetary configuration (a) and Eirich (right) with a co-current (b) and a counter-current (c) configuration.

\subsubsection{Videograder}

For the characterization of the aggregates grading curve, an optoelectronic device designed for rapid and repeatable analysis of the grading and particle shape of aggregate greater than $1 \mathrm{~mm}$ was used; the VDG 40.2 videograder [23]. The principle of the videograder is to take and analyze photos of shadows of backlighted particles. The available information on particle size and shape is therefore in 2D; results are then extrapolated to a three-dimension space with size expressed as an equivalent sieve diameter. 


\subsection{Testing methods}

\subsubsection{Mass loss characterization}

The mass loss of the coarse aggregate during mixing was measured. To do this, the fresh concrete was washed carefully and sieved to $2.5 \mathrm{~mm}$ after the mixing process. The recovered product greater than $2.5 \mathrm{~mm}$ was dried, then the aggregates were reweighed and the mass loss during mixing was calculated. The initial moisture of the aggregates was taken into account to calculate the mass loss.

\subsubsection{Grading and angularity characterization}

The grading of the recovered product greater than $2.5 \mathrm{~mm}$ was analyzed by the videograder. The measure was repeated three times for each sample in order to minimize the measurement error. The same tests allowed to measure the Angularity of particles, i.e. the mean value of the sharpest salient angles expressed as a dimensionless number between 0 (rounded aggregate) and 1 (angled aggregate) [24].

\subsection{Experimental program}

A total of 78 batches were carried out on the given concrete mixture. The experimental procedure was as follows:

- The solid materials were loaded in the same order; first the coarse aggregates, followed by the sand and the cement. After mixing for $35 \mathrm{~s}$ (dry mixing), water was added (wet mixing) and the complete mixture was mixed for different mixing times: 35 s, 55 s, 180 s or 300 s (Figure 2);

- After the mixing, the content of the mixer was carefully retrieved;

- The mixture was sieved under water on a $2.5 \mathrm{~mm}$ sieve and the recovered coarse aggregate (i.e. $>2.5 \mathrm{~mm}$ ) was dried in an oven at $70^{\circ} \mathrm{C}$ for at least 72 hours;

- The coarse aggregates were weighed short time after drying;

- $\quad$ The grading and angularity of the recovered product greater than $2.5 \mathrm{~mm}$ were measured.

This procedure was carried out for each mixing system, each mixing configuration and each kind of aggregate. For the planetary mixer, the configuration was the standard one and only the initial characteristics of aggregates were varied. For the Eirich mixer, the various parameters were: the initial aggregate status (resistance and moisture), the mixer speed and the mixer rotation direction. The following figure summarizes all the experimental tests made in this study. 


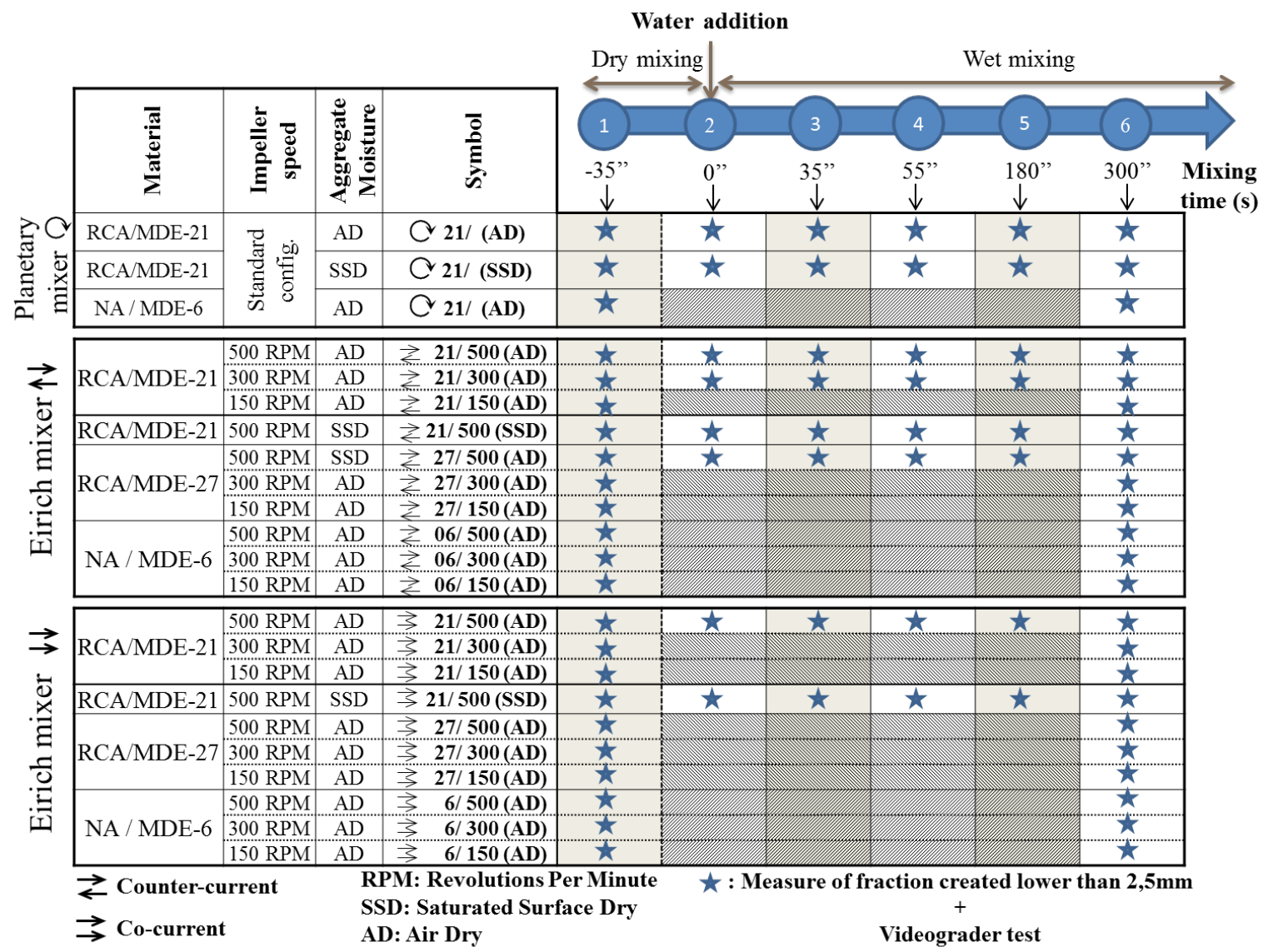

Figure 2. Experimental program.

\section{Results and discussions}

\subsection{Mass loss}

Figure 3 details the mass loss evolution with the mixing times for the different aggregates and mixer configurations. The origin of mixing time (time equal to zero) corresponds to the instant of the water addition after 35 seconds of dry mixing of all solid components. In Figure 3, the mass loss at the origin of mixing time corresponds to the effect of the 35 seconds of dry mixing.

During concrete laboratory production with the Eirich system, the mixing speed is commonly set between 150 and 300 RPM. We can observe that, for these mixing speeds in Eirich, the mass loss during several minutes of mixing was inferior to $1 \%$ for natural aggregate and inferior to $3 \%$ for RCA with an MDE of 21. Very similar trends were observed for the planetary mixing system in its usual laboratory configuration. The results corresponding to these frequent mixing conditions are highlighted in Figure 3. The lower quality RCA (MDE 27) produced higher aggregate degradation, up to about $5 \%$ of mass loss. Also, when the mixing speed is increased, the aggregate degradation enhanced. The extreme result was observed for the higher mixing speed in co-current configuration of the Eirich mixer. The mass loss level reached 11\% for RCA with MDE of 21 and 12.5\% for the lower quality RCA. It should be noted that for this mixing configuration, even the degradation of the natural aggregate was particularly high: mass loss up to $3.5 \%$.

The influence of the different material and process parameters on the mass loss is evaluated in the following. 


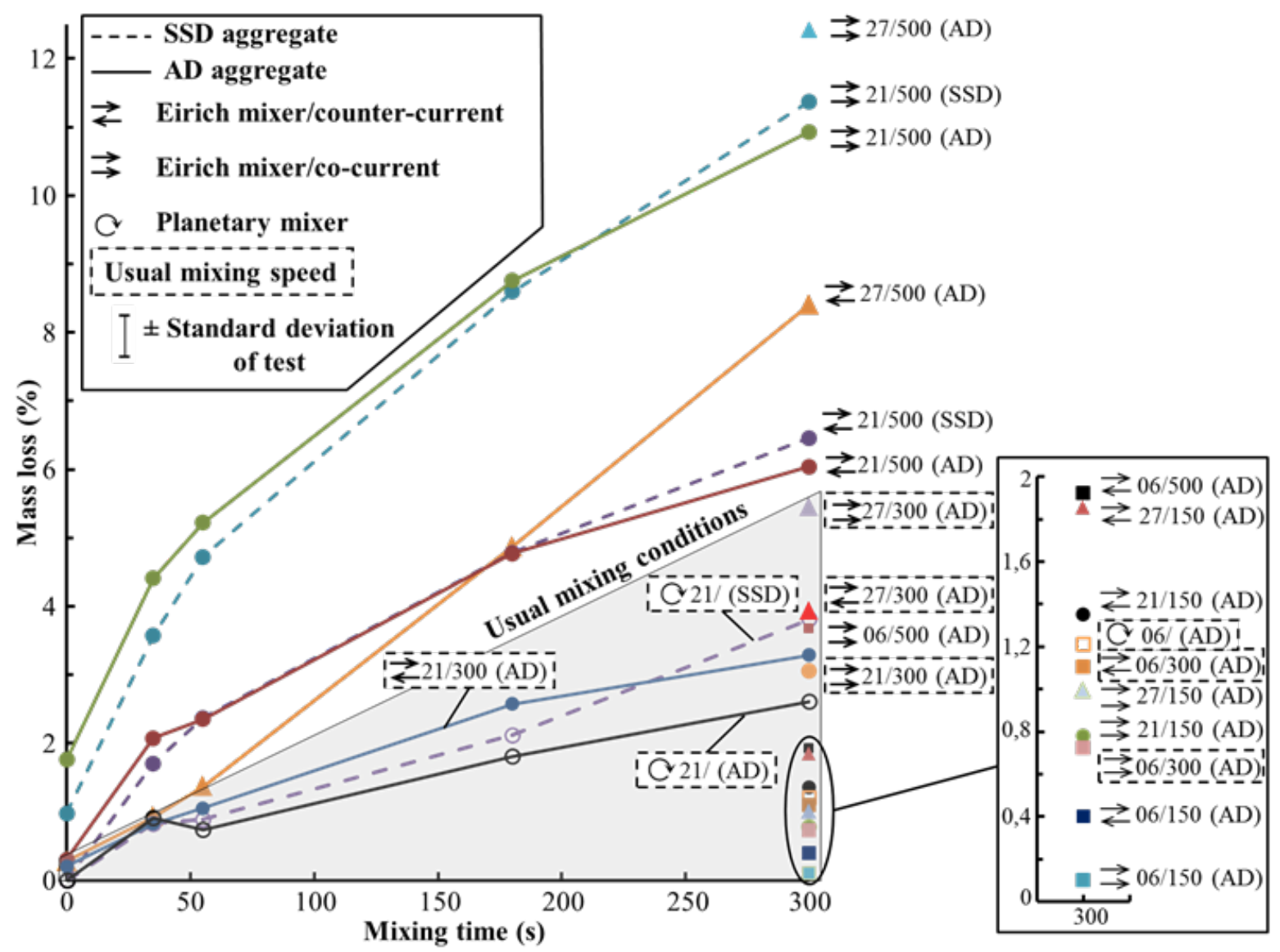

Figure 3. Mass loss over mixing time (time origin is the liquid loading time after 35 seconds of dry mixing).

\subsubsection{Dry and wet mixing}

In order to assess the influence of a dry mixing with respect of a wet mixing on the mass loss generated we plot in Figure 4 the mass loss obtained 35s after water addition ("wet mixing”) vs the mass loss in the first 35s of mixing prior to water addition (which we call "dry mixing", regardless of the initial moisture of the aggregates, in order to distinguish it from the mixing phase after water addition). We have to highlight that both mass losses are independent of each other. We can observe in all cases that the points are located over the equality line; this means that the "wet mixing" phase was more aggressive than the "dry mixing" phase regardless of the initial moisture of the aggregate. The mass loss during the "wet mixing" can be even doubled with respect to the mass loss during the "dry mixing”.

This phenomenon can be explained by the fact that when the liquid is loaded to the mixer, the medium suddenly compacts due to liquid-induced cohesion, and this probably leads to higher stresses on the aggregates. It was already shown for concrete mixing that, after the liquid addition an increase in the power consumption in the mixer is found, which corresponds to an increase in the mixing energy [25]. This supports the idea that higher stresses develop in the mix after the liquid addition, and that they are the source of the increased mass loss. 


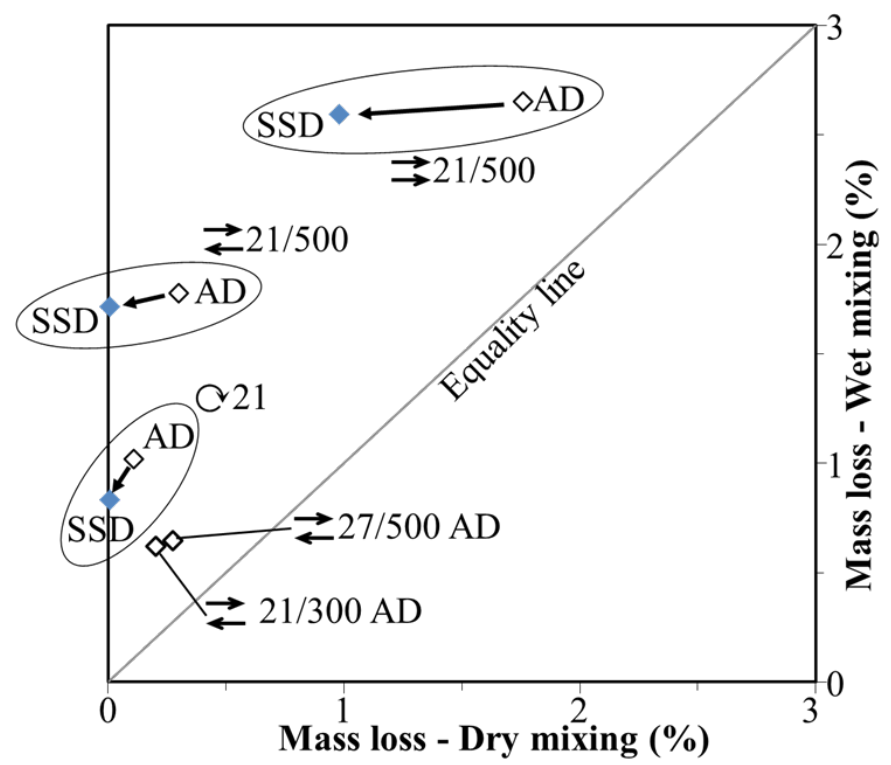

Figure 4. Mass loss during wet mixing Vs mass loss during dry mixing (after $35 \mathrm{~s}$ of mixing).

\subsubsection{Initial moisture of the aggregate}

Figure 4 shows also the influence of the initial moisture of the aggregates in the mass loss during the dry mixing and during the wet mixing. The degradation of the initially AD aggregate was significantly higher during the "dry mixing" than the degradation of the initially SSD aggregates. A coating of the aggregates by powder during the "dry mixing" could explain this phenomenon. Indeed, we can expect that the coating of aggregates by powder should be amplified for initially SSD aggregates compared with initially AD particles. Since the surface of the SSD aggregates is slightly wet, a layer of powder is created during the "dry mixing" that protect them. We can also observe that, conversely, the degradation during the wet mixing wasn't significantly changed by the initial moisture of the aggregate. The powder layer is dissolved when the liquid is loaded and the SSD aggregates are then exposed in the same way that the AD ones.

This is confirmed whatever the mixing configuration, by comparing the behavior of the initially saturated surface dry (SSD) and air dry (AD) aggregate at different wet mixing times (Figure 3). However, the last point of the planetary mixer (at $300 \mathrm{sec}$ of mixing time) seems to have a different behavior. A statistical Cochran test was carried out resulting in that the point of the initially SSD aggregates at 300 sec of mixing for the planetary mixer is aberrant. We will then not consider this point hereafter. The repeatability of the tests can be coarsely assessed by considering that the difference between the SSD and AD aggregate mass loss major the mass loss accuracy. This level of experimental error is represented in Figure 3. 


\subsubsection{Mixing time}

Power law curves fit well (determination coefficients $\mathrm{R}^{2}$ higher than 0.98 ) the evolution of the mass loss $\Delta M$ with the mixing time, $t$ :

$$
\Delta M \propto t^{n}
$$

The index $n$ of these fitting curves is given Figure 5 as function of the tested configuration. When available, the mean values from the SSD and AD aggregates of a same configuration were considered in order to increase the precision of interpolation.

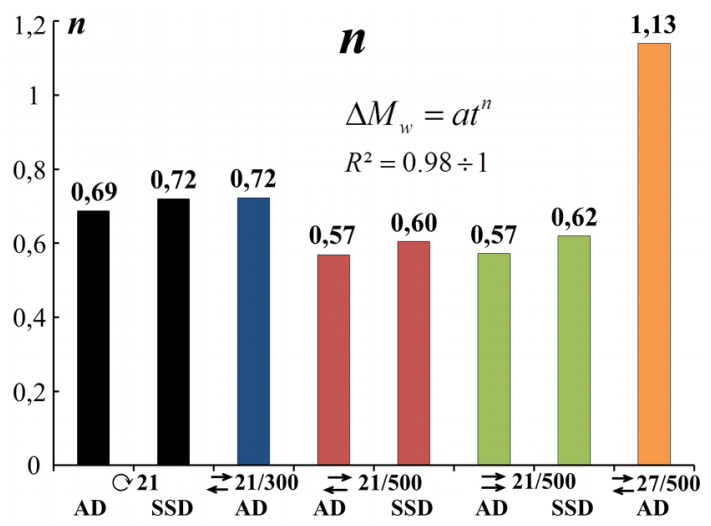

Figure 5. Index $n$ of the fitting power law of the mass loss evolution for the tested mixing configurations.

The mass loss rate decreased with the mixing time $(n<1)$ for the good abrasion resistance RCA (MDE 21 ), while the behavior was closer to linear for the aggregates with a lower abrasion resistance. It should be noted that a classical attrition model [26] predicts a linear evolution of mass loss as a function of time. A linear behavior is observable also in the data presented by González Ortega [17] for three different natural aggregates.

We suggest that the different behavior displayed by aggregates characterized by different initial MDE value was a consequence of the different amounts of mortar in the RCA. It is important to note that the lower abrasion resistance RCA (MDE 27) were obtained by density stratification and that the lower density is associated to higher mortar content.

In particular, it is reasonable to assume that for the aggregates with higher density (and lower MDE value); it is likely that the degradation occurred on both mortar and original aggregate. It is probable that during mixing, the coarse aggregates became progressively poor in mortar and more and more original aggregates from these RCA were exposed to abrasion. For this reason the aggregate strength could be increased and the attrition rate reduced. Also, as the interface between mortar and natural aggregate is generally less strong than the internal cohesion of a single-phase material, mortar is detached quicker from the higher density RCA which could explain the higher initial mass loss of these aggregates (for similar assumptions, see also Soares [27]).

The power law index $\mathrm{n}$ was similar for same mixing speeds, in co and counter-current configurations. However, it should be observed that the mass loss is mostly twice in the co-current configuration. The power law index also confirmed that the behavior in the planetary mixer is very close to the behavior in the Erich mixer at 300 RPM mixing speed. 
As concerns the aggregates characterized by a lower abrasion resistance (MDE 27), the nearly linear evolution of the attrition rate could be explained by the fact that they behave as if they were composed only by mortar, at least for the mixing time considered.

\subsubsection{Mixing speed and direction}

The mass loss was measured at different speeds (150, 300 and 500 RPM) in the two mixing directions for the Eirich mixer, setting the mixing time at 300 seconds (Figure 6a). The mixing speed is directly related to the mixing energy so one might expect an increase of the mass loss with the mixing speed, $\omega$. Indeed it is what happened, the mass loss increased with the mixing speed. A power law fits this evolution with determination coefficients higher than 0.99 :

$$
\Delta M \propto \omega^{m} \quad \text { (2). }
$$

The values of the power law indexes $m$ (Figure 6b) show that the effect of the mixing speed on the mass loss was different for the two Erich mixer configurations:

- in the counter-current movement, the mass loss increased almost linearly with the mixing speed (index of the power law close to 1)

- in the co-current movement the mass loss increased much faster than the mixing speed (index of the power law significantly higher than 1 ).

It occurs that the co-current configuration was less aggressive than the counter-current configuration at low mixing speed. At high mixing speed, the co-current configuration was more aggressive. A possible explanation of these observations may lie in the different structure of the granular flow in the two configurations, imposing different abrasion mechanisms. In co-current movement we can expect that the material is constricted between the impeller and the vessel. In counter-current configuration the abrasion was more likely to be due to the effect of the impacts of the material with the impeller which movement was opposed to the flow produced by the vessel. 

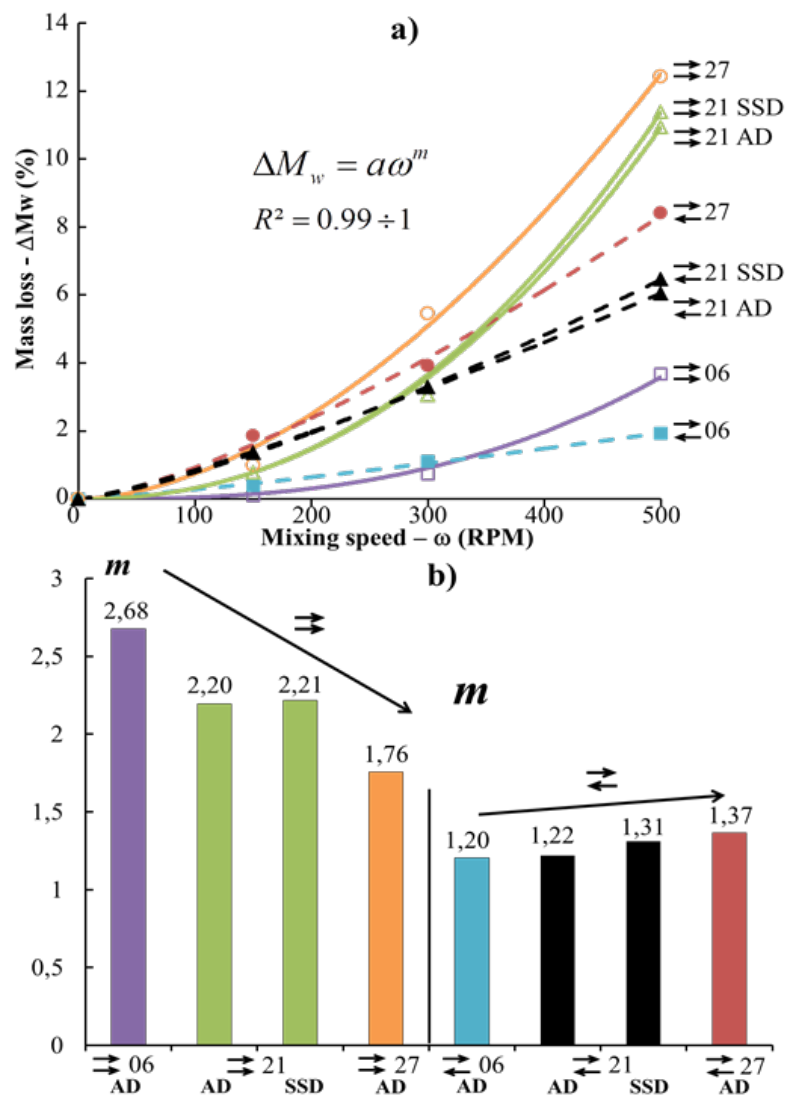

Figure 6. a) Evolution of the mass loss with the mixing speed at 300 second, for the two directions of the agitator of the Eirich mixer and the different MDE values, b) Evolution of the power law index fitting the mass loss evolution with the mixing speed with the MDE value, for the co and countercurrent configuration in the Eirich mixer.

\subsubsection{Abrasion resistance of aggregates}

For long mixing times, the mass loss increases with the MDE value, in all mixing configurations (Figure 7). One must however recall that the behavior could be different for a short mixing time (see the discussion in section 3.1.3). The MDE value also influences the power law index $m$ (Figure 6b):

- it drastically decreased in the co-current configuration, so the effect of the mixing speed is higher for aggregates more sensitive to abrasion;

- it slightly increased in the co-current configuration; we can deduce that the intensity of constriction or impacts affects differently the fracturing of the aggregates in function of their strength, but more specific research is needed to deepen this assumption. 


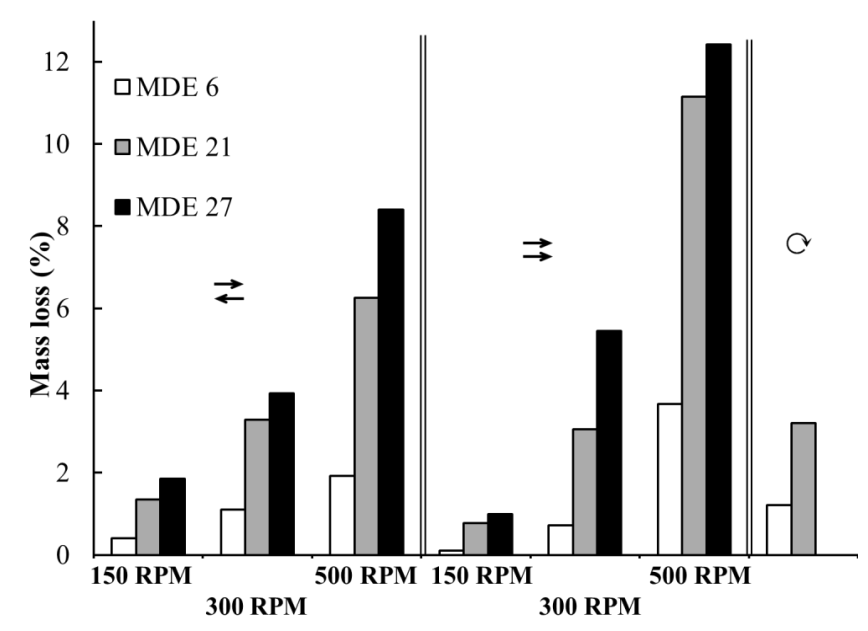

Figure 7. Influence of the MDE value on the mass loss at 300 second, for the different mixing configurations (counter-current Eirich mixer, co-current Eirich mixer and planetary mixer) and mixing speeds.

\subsection{Particle size evolution}

In complement to the mass loss measurement (mass of the particles with size inferior to $2.5 \mathrm{~mm}$ created under shear), the mechanisms of fracture of the aggregates during mixing were assessed by analyzing the evolution of the grading curves of the particles larger than $2.5 \mathrm{~mm}$. In this chapter we intend to confirm the above points discussed and providing a study of the fracture mechanisms involved during mixing. The results discussed above correspond only to the wet mixing. The proportion of intermediate particles with size between 2.5 and $10 \mathrm{~mm}$ created during mixing is considered here as an indicator of the cleavage mechanism intensity, as opposite to the attrition mechanism which produces particles of smaller size (between 0 and $2.5 \mathrm{~mm}$ ). A description of different breakage mechanisms can be found in [26].

\subsubsection{Mixing time}

Figure 8 represents the evolution of cumulative particles size distribution during the mixing time for the higher quality RCA (MDE-21 / AD) in the Eirich mixer in the co-current configuration at 500 RPM and in the planetary mixer (the particles with size inferior to $2.5 \mathrm{~mm}$ are included). We can observe in Figure 8a that we have a large evolution after only $35 \mathrm{sec}$ of wet mixing and an evolution rate that decreases with time. We observe the same behavior in Figure $8 \mathrm{~b}$ for the planetary mixer but with a less pronounced initial evolution. This is consistent with the previously discussion in section 3.1.3 about the structure of the RCA with MDE-value of 21 composed from two phases: original aggregates and mortar.

The high rates of mass loss $(<2.5 \mathrm{~mm})$ observed in previous section 3 for the Eirich mixer combined with the bimodal behavior of the grading curves (Figure 8a), indicate that the attrition is the predominant fracture mechanism involved during mixing in an Eirich mixer. However, the intermediate fraction (between 2.5 and $10 \mathrm{~mm}$ ) seems to evolve during mixing time but in a less important way, the flat plateau in the cumulative distribution (characteristic of attrition mechanism) decreases with mixing time. We can conclude that probably a weak cleavage fracture mechanism is also present during the mixing.

On the other hand, the lower mass loss observed in the planetary mixer and the more important intermediate fraction with a size between 2.5 and $10 \mathrm{~mm}$ created in proportion to the mass loss $(<2.5$ 
$\mathrm{mm}$ ) indicates that an attrition mechanism is combined with a cleavage fracture mechanism. The cleavage is the main fracture mechanism involved in a planetary mixer.
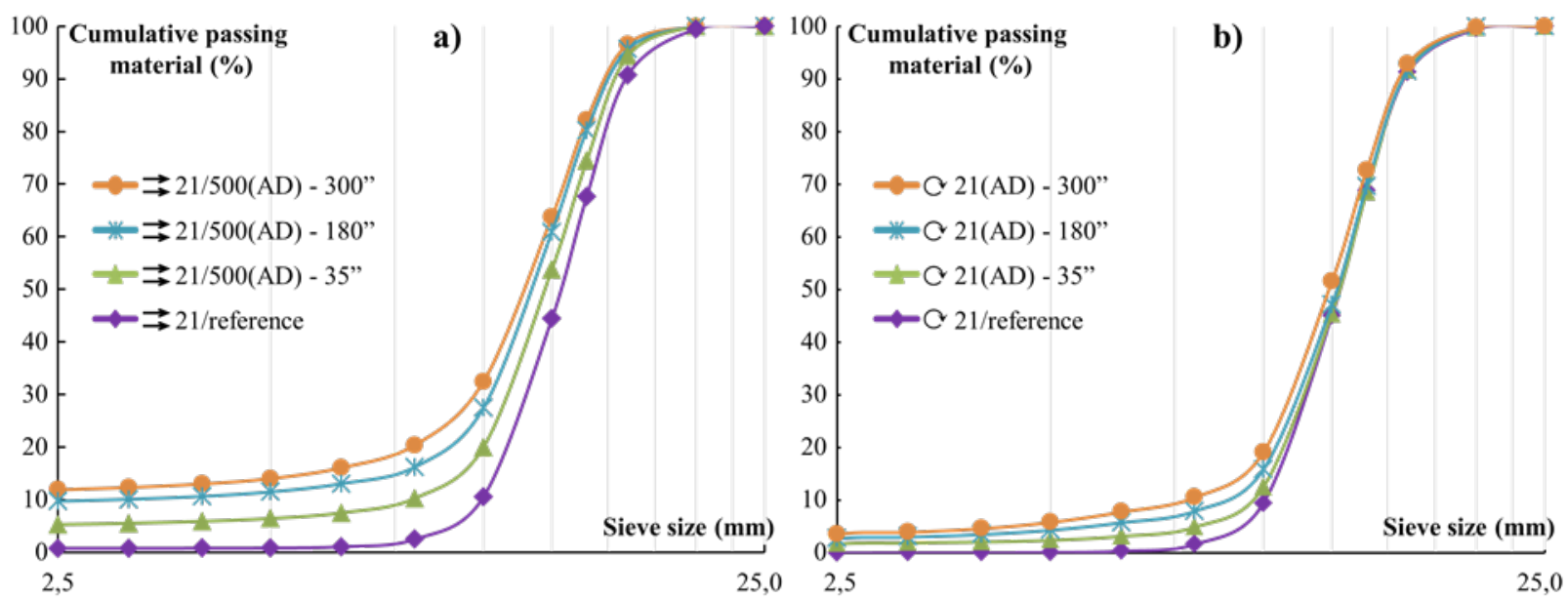

Figure 8. Grading curves evolution including particles smaller to $2.5 \mathrm{~mm}$, depending on mixing time for the higher quality RCA (MDE-21) in the a) Eirich mixer in the co-current configuration at 500 RPM and b) the planetary mixer.

\subsubsection{Mixing system}

By analyzing the grading curves evolution of the high quality RCA (MDE-21) with the mixing time in the Eirich co-current configuration at the higher mixing speed and in the planetary mixer (Figure 8) a significant different behavior can be observed. In the planetary mixer, the content in coarsest particles (size superior to $12.5 \mathrm{~mm}$ ) only slightly diminished during mixing. This is not the case in the given Eirich mixing configuration.

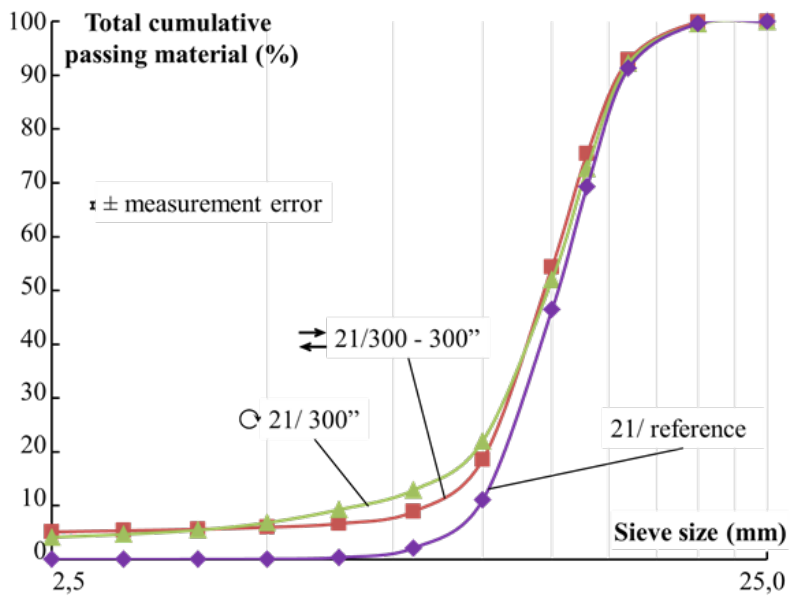

Figure 9. Grading curves evolution including particles smaller to $2.5 \mathrm{~mm}$ before mixing and after mixing in the two mixing system, Eirich mixer in the counter-current configuration at 300 RPM and the planetary mixer, at the longest mixing time for the higher quality RCA (MDE-21).

The same phenomenon was observed when comparing the planetary mixer with the Eirich mixer at 300 RPM in counter-current configuration (Figure 9). These two configuration have been chosen as it was found in previous chapters that they behavior are very close. For a similar amount of particles inferior to $2.5 \mathrm{~mm}$ (see Figure 7), the planetary mixer produced more intermediate fractions (larger than 2.5 and lower than $10 \mathrm{~mm}$ ), and broke slightly less large particles. We can expect that in the planetary mixer, the particles with size close to the size of the gap between the blade and the vessel 
(which is 5 to $10 \mathrm{~mm}$ ) were preferentially broken by the mixer. This confirms the presence of a cleavage mechanism of fracture produced in the intermediated particle by the blade and the vessel that tends to produce several relatively large fragments. Conversely, the particles larger than this size are probably only leveled by the blade and are less subject to shear. In the Eirich mixer, the gap between the blades and the vessel is much higher and the wear of the particles is produced independently of the particles size.

The influence of the mixing speed in the Eirich counter-current configuration can be observed in Figure 10a. The slower mixing speed almost did not change the size distribution. The small amount of fines created was produced only by slight attrition of the coarse aggregate. For higher mixing speeds of 300 and 500 RPM, the grading evolution was more important but similar between them. We can consider that the attrition mechanism of the particles needed a shearing threshold. It should be pointed out that the amount of fine elements increased with the mixing speed (Figure 6a) so the attrition and the cleavage mechanisms seem to depend differently on the mixing speed in the Eirich mixer.

At the lowest mixing speed, there was no significant difference observed between the Eirich co-current and counter-current mixing configurations (Figure 10b). The only mechanism of size reduction is the attrition, which seems more pronounced in the counter-current flow (Figure 7). At the highest speed, the cleavage mechanism is present in both configurations, but is considerably greater in the co-current mechanism.
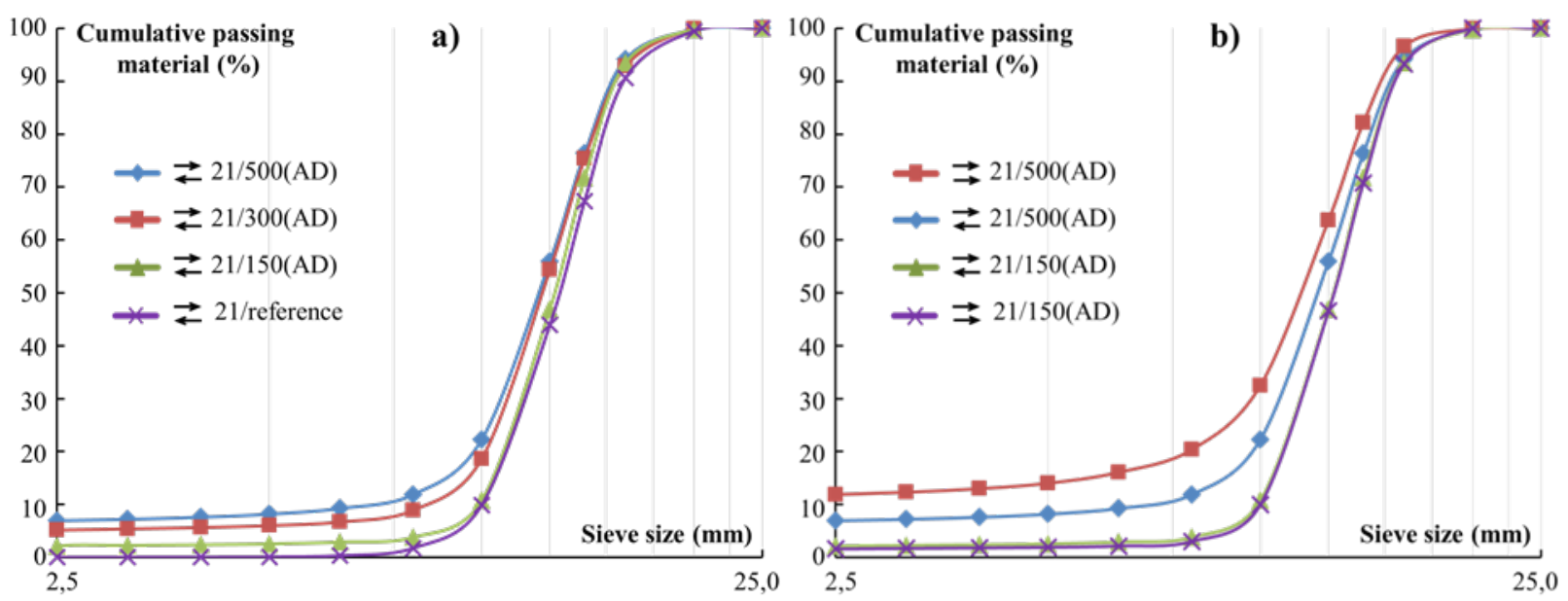

Figure 10. Grading curves evolution including particles smaller to $2.5 \mathrm{~mm}$ for the higher quality RCA

(MDE-21), depending on a) mixing speed at $300 \mathrm{sec}$ and b) rotation direction at 300 sec.

\subsubsection{Initial moisture and strength of aggregates}

In both co-current and counter-current Erich mixer configuration, the size of the aggregates after the mixing was identical for the initially SSD and the initially AD recycled concrete particles. The Figure 11a illustrates this observation for the highest mixing speed. It results that the attrition and cleavage mechanisms are not influenced by the initial moisture of the RCA. 

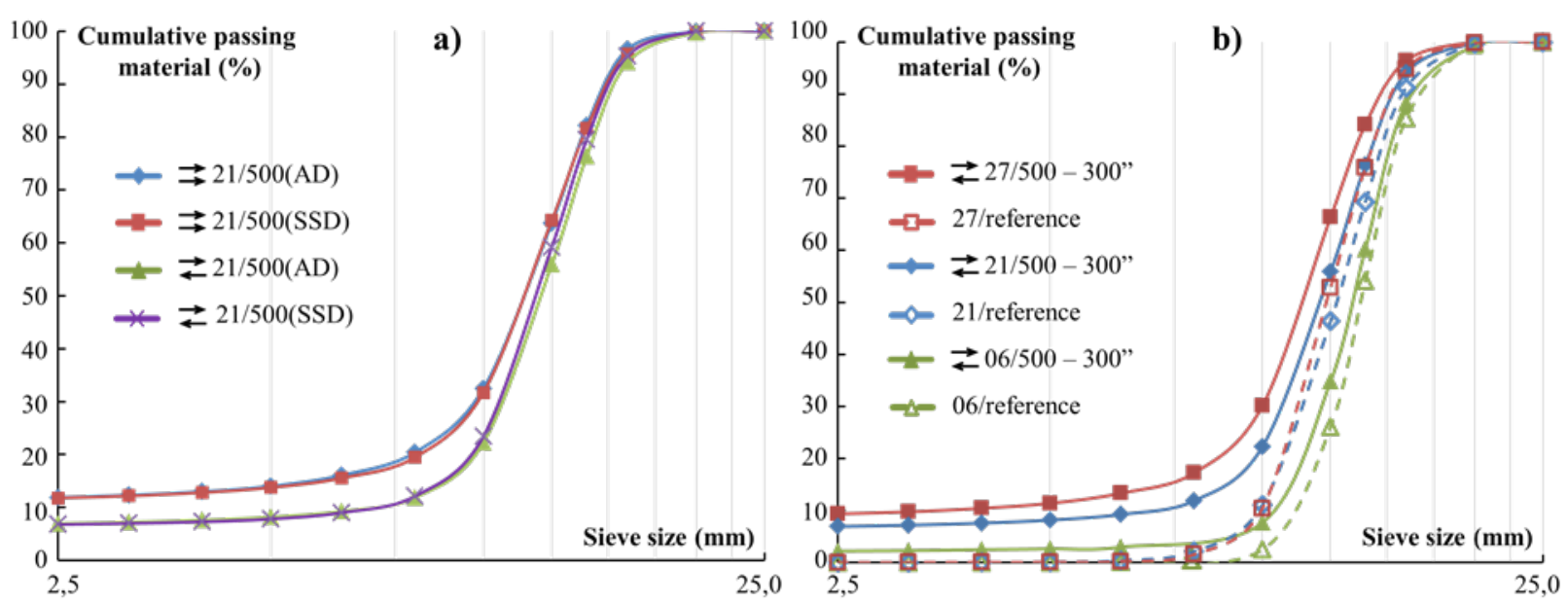

Figure 11. Grading curves evolution including particles smaller to $2.5 \mathrm{~mm}$ in the Eirich mixer in the counter-current configuration at 500 RPM, depending on the a) initial moisture of the higher quality RCA (MDE-21) and b) material initial abrasion resistance, by indicating for each case the grading before mixing (reference, dashed lines) and after 300 seconds of mixing (solid lines).

As expected, the attrition strength of the aggregates introduced a different behavior regarding the evolution of the grading curve during mixing. The grading curves before and after 300 seconds of mixing are given in Figure 11b, for the natural aggregate (MDE-06), the high quality RCA (MDE-21) and for the lower quality RCA (MDE-27), in the counter-current configuration of the Eirich mixer. We can observe that the evolution of particles size is higher when the MDE value increases.

\subsection{Angularity evolution}

The variation of the angularity of the aggregates was measured for some selected cases, which were judged as the most representative configurations. Results are presented in Figure 12. In their studies, Bessa et al. [28] and Tolppanen et al. [29] observed that different aggregates lost some surface texture and angularity after abrasion and polishing procedures concluding that the aggregates' surface become smoother and their edges more rounded. This was also our case: in all the tests for which the angularity of the aggregates was measured, it was clearly reduced by the mixing. It should be noted however that the mixing in the planetary mixer produced only a slight, statistically irrelevant diminution of the angularity. This may be related to the fracture mechanisms occurring in the planetary mixer: in section 3.2.1 it was argued that cleavage fracture was important in the planetary mixer. This kind of breakage produces less rounded particles than attrition: the angularity evolution therefore supports the idea that the breakage mechanisms in the planetary and Eirich mixer may be qualitatively different. On the other hand, the reduction in angularity of the less resistant RCA (MDE-value of 27) was the most important. 


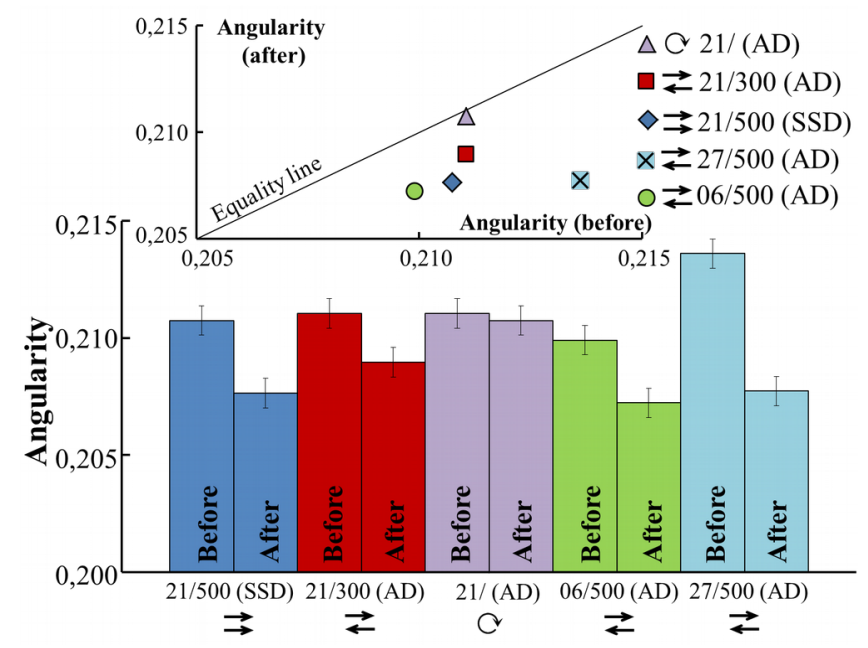

Figure 12. Angularity evolution of aggregates. Results correspond to the aggregates angularity before the mixing compared with the angularity at the end of the mixing, i.e. after 300 of mixing.

\section{Conclusions}

This work evaluated the coarse RCA mass and grading evolution with respect to different mixing methods, at laboratory scale. Some comparisons were made with the behavior of natural aggregates of the same size. The following conclusions were drawn:

- Very similar trends were observed for the planetary mixing system and for the Eirich mixer in their usual laboratory configurations. It should be emphasized that for these common laboratory production operating conditions, the degradation of natural aggregate during mixing is almost negligible. The fraction inferior to $2.5 \mathrm{~mm}$ of an initially $10-14 \mathrm{~mm}$ aggregate is less than $1 \%$ of the coarse aggregate mass. This percentage increases up to 3\% for good quality RCA (MDE value of 21) and to 5\% for lesser quality RCA (MDE value of 27). In industrial scale mixers, one can suppose significantly smaller degradation; indeed, the mixing time is generally significantly lower in high capacity mixers, and the shearing is generally smaller (see for instance Chopin et al. 2007). It is then expected that the fracturing of the RCA contributes to the difficulties to scale-up the recycled aggregate concrete mixdesign from the laboratory to the industrial plant.

- The degradation of the RCA drastically increased when the mixing speed was raised to 500 RPM for the Eirich Mixer.

- The dry mixing (before the liquid loading) was about two times less aggressive than the wet mixing (with all water). However, the degradation of initially saturated RCA was significantly reduced compared with that of air dried aggregates during the dry mixing. No effect of the initial moisture of the RCA was observed during the wet mixing. It seems that the powder coating of the aggregates created during the dry mixing protected the coarse particles from fracturing.

- The mixing parameters influenced the mass loss rate during mixing, i.e. the higher the mixing time and speed, the greater the mass loss. The impeller rotation direction induces different patterns of the aggregates shearing. In the counter-current movement the mass loss increased almost linearly with the mixing speed. In the co-current movement the mass loss increased much faster than the mixing speed. 
- RCA with a lower attrition resistance suffered a progressive mass loss behaving as a single-phase material, conversely to the good quality RCA that suffered a nonlinear degradation in mixing time, due to their biphasic behavior.

- In the planetary mixer, the particles with size close to the size of the gap between the blade and the vessel (which is around $10 \mathrm{~mm}$ ) were in priority broken by the mixer. In the Eirich mixer, the wear of the particles is produced independently of the sizes of the particles.

- It was shown that both attrition and cleavage mechanisms influenced the aggregate degradation. In the Eirich mixer, the attrition mechanism was more pronounced and was more noticeable for aggregates with higher abrasion resistance and at high mixing speed. The cleavage of the particles needed a threshold of shearing. This is not the case for the attrition mechanism.

- The angularity of the RCA was reduced by the mixing and this effect was increased for aggregates with low abrasion resistance.

\section{Acknowledgements}

The "Projet National Recybéton” financially supported this study. 


\section{References}

[1] M. Etxeberria, E. Vázquez, A. Marí, M. Barra, Influence of amount of recycled coarse aggregates and production process on properties of recycled aggregate concrete, Cem. Concr. Res. 37 (2007) 735-742.

[2] T.C. Hansen, Recycling of Demolished Concrete and Masonry, RILEM, 1992.

[3] K.K. Sagoe-Crentsil, T. Brown, A.H. Taylor, Performance of concrete made with commercially produced coarse recycled concrete aggregate, Cem. Concr. Res. 31 (2001) 707-712.

[4] Z. Hua Duan, C. Sun Poon, Properties of recycled aggregate concrete made with recycled aggregates with different amounts of old adhered mortars, Mater. Des. 58 (2014) 19-29.

[5] M. Sánchez de Juan, P. Alaejos Gutiérrez, Study on the influence of attached mortar content on the properties of recycled concrete aggregate, Constr. Build. Mater. 23 (2009) 872-877.

[6] A. Abbas, G. Fathifazl, B. Fournier, O.B. Isgor, R. Zavadil, A.G. Razaqpur, et al., Quantification of the residual mortar content in recycled concrete aggregates by image analysis, Mater. Charact. 60 (2009) 716-728.

[7] P. Belin, G. Habert, M. Thiery, N. Roussel, Cement paste content and water absorption of recycled concrete coarse aggregates, Mater. Struct. 47 (2013) 1451-1465.

[8] P. Gonçalves, J. De Brito, Recycled aggregate concrete (RAC) - comparative analysis of existing specifications, Mag. Concr. Res. 62 (2010) 339-346.

[9] A. Barbudo, F. Agrela, J. Ayuso, J.R. Jiménez, C.S. Poon, Statistical analysis of recycled aggregates derived from different sources for sub-base applications, Constr. Build. Mater. 28 (2012) 129-138.

[10] C.J. Zega, A.A. Di Maio, Recycled concrete made with different natural coarse aggregates exposed to high temperature, Constr. Build. Mater. 23 (2009) 2047-2052.

[11] D.T. Dao, T. Sedran, F. De Larrard, Optimization of the recycling of concrete in concrete: application to an airport slab, in: 12th Int. Symp. Concr. Road, Prague, Czech Republic, n.d.

[12] A. Akbarnezhad, K.C.G. Ong, C.T. Tam, M.H. Zhang, Effects of the Parent Concrete Properties and Crushing Procedure on the Properties of Coarse Recycled Concrete Aggregates, 25 (2013) 1795-1802.

[13] R. Artoni, B. Cazacliu, E. Hamard, A. Cothenet, Resistance to fragmentation of recycled concrete aggregates, submitted (2015).

[14] B. Schouenborg, J. Aurstad, L. Hagnestål, P. Petursson, J. Winblad, Test Methods Adapted for Alternative and Recycled, Porous Aggregate Materials, (n.d.).

[15] M. Quattrone, B. Cazacliu, S.C.Angulo, E. Hamard, A. Cothenet, Measuring the water absorption of recycled aggregates, what is the best practice for concrete production?, submitted to Constr. Build. Mater. 
[16] J. Bridgwater, Particle Breakage due to Bulk Shear, Handbook of Powder Technology, 2007, vol. 12, pp. 87-116.

[17] M.A. González Ortega, S.H.P. Cavalaro, A. Aguado, Influence of barite aggregate friability on mixing process and mechanical properties of concrete, Constr. Build. Mater. 74 (2015) 169-175.

[18] C.S. Poon, Z.H. Shui, L. Lam, H. Fok, S.C. Kou, Influence of moisture states of natural and recycled aggregates on the slump and compressive strength of concrete, Cem. Concr. Res. 34 (2004) $31-36$

[19] H. Mefteh, O. Kebaïli, H. Oucief, L. Berredjem, N. Arabi, Influence of moisture conditioning of recycled aggregates on the properties of fresh and hardened concrete, J. Clean. Prod. 54 (2013) 282-288.

[20] AFNOR. (2012). Essais pour béton frais - Partie 2 : essai d'affaissement. NF EN 12350-2, AFNOR, Saint-Denis La Plaine, France (in French)

[21] AFNOR. (2011). Essais pour déterminer les caractéristiques mécaniques et physiques des granulats - Partie 1 : détermination de la résistance à l'usure (micro-Deval). NF EN 1097-1, AFNOR, Saint-Denis La Plaine, France (in French)

[22] B. Cazacliu, C.H. Sampaio, G. Miltzarek, C. Petter, L. Le Guen, R. Paranhos, et al., The potential of using air jigging to sort recycled aggregates, J. Clean. Prod. 66 (2014) 46-53.

[23] A.M. Pham, Y. Descantes, F. De Larrard, Determination of sieve grading curves using an optical device, Mechatronics. 21 (2011) 298-309.

[24] Y. Descantes, Y. Fosse, F. Milcent, Automated Measurement of Railway Ballast Angularity, J. Mater. Civ. Eng. 18 (2006) 612-618.

[25] B. Cazacliu, N. Roquet Concrete mixing kinetics by means of power measurement. Cem. Concr. Res. 39 (2009) 182-194.

[26] R.P. King, Modelling \& Simulation of Mineral Processing Systems, Boston, 2001.

[27] D. Soares, J. De Brito, J. Ferreira, J. Pacheco, Use of coarse recycled aggregates from precast concrete rejects : Mechanical and durability performance, Constr. Build. Mater. 71 (2014) 263-272.

[28] I.S. Bessa, V.T.F. Castelo Branco, J.B. Soares, Evaluation of polishing and degradation resistance of natural aggregates and steel slag using the aggregate image measurement system, Road Mater. Pavement Des. 15 (2014) 385-405.

[29] P. Tolppanen, O. Stephansson, L. Stenlid, 3-D degradation analysis of railroad ballast, Bull. Eng. Geol. Environ. 61 (2002) 35-42. 


\section{ANNEXES}

Annex A. Properties of the aggregates

Table A.1.1. Properties of the coarse recycled aggregates used in this study

\begin{tabular}{|c|c|c|c|c|c|c|c|c|c|}
\hline $\begin{array}{c}\text { Aggregate } \\
\text { Type }\end{array}$ & Origin & $\begin{array}{c}\text { Size } \\
(\mathrm{mm})\end{array}$ & $\begin{array}{c}\text { Los } \\
\text { Angeles } \\
(\%)\end{array}$ & $\begin{array}{c}\text { Micr } \\
\mathrm{o} \\
\text { Deval } \\
(\%)\end{array}$ & $\begin{array}{c}\text { Density } \\
\left(\mathrm{kg} / \mathrm{m}^{3}\right)\end{array}$ & $\begin{array}{c}\text { Water } \\
\text { absorption } \\
(\%)\end{array}$ & $\begin{array}{c}\text { Sulphate } \\
\text { content } \\
\mathrm{SO}_{4}^{2-}(\%)\end{array}$ & $\begin{array}{c}\text { Chloride } \\
\text { ion } \\
\text { content } \\
\mathrm{Cl}^{-}(\%)\end{array}$ & $\begin{array}{c}\text { Flattening } \\
\text { coefficien } \\
\mathrm{t} \\
\mathrm{Fl}(\%)\end{array}$ \\
\hline $\begin{array}{c}\text { Recycled } \\
\text { concrete } \\
\text { aggregate } \\
\text { (RCA) }\end{array}$ & $\begin{array}{c}\text { Gonesse } \\
\text { (France) }\end{array}$ & $10-14$ & 32 & 21 & 2260 & 5,6 & 0,19 & 0,03 & 4 \\
\hline $\begin{array}{c}\text { Recycled } \\
\text { concrete } \\
\text { aggregate } \\
\text { (RCA) }\end{array}$ & $\begin{array}{c}\text { Gonesse } \\
\text { (France) }\end{array}$ & $10-14$ & 35 & 27 & 2159 & 7,0 & 0,19 & 0,03 & - \\
\hline
\end{tabular}

Table A.1.2. Properties of the coarse natural aggregates used in this study

\begin{tabular}{|c|c|c|c|c|c|c|c|c|c|}
\hline $\begin{array}{c}\text { Aggregat } \\
\text { e Type }\end{array}$ & Origin & $\begin{array}{c}\text { Geologi } \\
\text { c nature }\end{array}$ & $\begin{array}{c}\text { Size } \\
(\mathrm{mm} \\
)\end{array}$ & $\begin{array}{c}\text { Los } \\
\text { Angele } \\
\mathrm{s}(\%)\end{array}$ & $\begin{array}{c}\text { Micr } \\
\mathrm{o} \\
\text { Deval } \\
(\%)\end{array}$ & $\begin{array}{c}\text { Densit } \\
\mathrm{y} \\
\left(\mathrm{kg} / \mathrm{m}^{3}\right)\end{array}$ & $\begin{array}{c}\text { Water } \\
\text { absorptio } \\
\mathrm{n}(\%)\end{array}$ & $\begin{array}{c}\text { Flattening } \\
\text { coefficien } \\
\mathrm{t} \\
\mathrm{Fl}(\%)\end{array}$ & $\begin{array}{c}\text { Accelerate } \\
\mathrm{d} \text { polishing } \\
\text { coefficient } \\
\text { PSV }\end{array}$ \\
\hline $\begin{array}{c}\text { Natural } \\
\text { aggregate } \\
\text { (NA) }\end{array}$ & $\begin{array}{c}\text { Pontreau } \\
\mathrm{x} \\
\text { (France) }\end{array}$ & $\begin{array}{c}\text { Gneiss / } \\
\text { Crushed }\end{array}$ & $\begin{array}{c}10- \\
14\end{array}$ & 15 & 6 & 2636 & 0,3 & 8,5 & 53 \\
\hline
\end{tabular}

Table A.1.3. Properties of the natural sand used in this study

\begin{tabular}{|c|c|c|c|c|c|c|c|c|c|}
\hline $\begin{array}{c}\text { Aggregat } \\
\text { e Type }\end{array}$ & Origin & $\begin{array}{c}\text { Geologic } \\
\text { nature }\end{array}$ & $\begin{array}{c}\text { Size } \\
(\mathrm{mm})\end{array}$ & $\begin{array}{c}\text { Density } \\
\left(\mathrm{kg} / \mathrm{m}^{3}\right)\end{array}$ & $\begin{array}{c}\text { Water } \\
\text { absorption } \\
(\%)\end{array}$ & $\begin{array}{c}\text { Sulphat } \\
\text { e } \\
\text { content } \\
\mathrm{SO}_{4}^{2-} \\
(\%)\end{array}$ & $\begin{array}{c}\text { Chlorid } \\
\text { e ion } \\
\text { content } \\
\mathrm{Cl}^{-}(\%)\end{array}$ & $\begin{array}{c}\text { Finenes } \\
\mathrm{s} \\
\text { Modulu } \\
\mathrm{s} \\
\mathrm{FM}\end{array}$ & $\begin{array}{c}\text { Organic } \\
\text { pollutant } \\
\mathrm{s}\end{array}$ \\
\hline $\begin{array}{c}\text { Natural } \\
\text { sand }\end{array}$ & $\begin{array}{c}\text { Pilier } \\
\text { (France) }\end{array}$ & $\begin{array}{c}\text { Silico- } \\
\text { calcareou } \\
\text { s/ Marine } \\
\text { alluvial }\end{array}$ & $0-2,5$ & 2600 & 0,6 & 0,086 & 0,0047 & 2,86 & negative \\
\hline
\end{tabular}


Annex B. Mass loss results from all the tests

\begin{tabular}{|c|c|c|c|c|c|c|c|c|c|c|}
\hline \multirow{3}{*}{ 离 } & \multirow{3}{*}{ } & \multirow{3}{*}{ 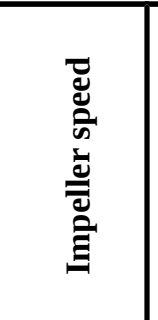 } & \multirow{3}{*}{ 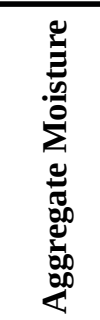 } & \multirow{3}{*}{ 容 } & \multirow{2}{*}{\multicolumn{6}{|c|}{$\begin{array}{c}\text { Mass loss (\%) } \\
\text { Mixing Time (sec) }\end{array}$}} \\
\hline & & & & & & & & & & \\
\hline & & & & & -35 & 0 & 35 & 55 & 180 & 300 \\
\hline \multirow{3}{*}{ 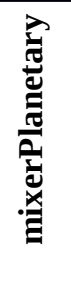 } & $\begin{array}{c}\text { RCA/MDE- } \\
21\end{array}$ & \multirow{3}{*}{ 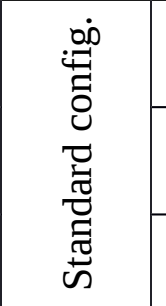 } & $\mathrm{AD}$ & $\mathrm{C}_{21 /(\mathrm{AD})}$ & 0 & 0 & 0,911 & 0,735 & 1,809 & 2,608 \\
\hline & $\begin{array}{c}\text { RCA/MDE- } \\
21\end{array}$ & & SSD & $\mathrm{C}_{21 /(\mathrm{SSD})}$ & 0 & $-0,007$ & 0,825 & 0,887 & 2,117 & 3,816 \\
\hline & NA / MDE-6 & & $\mathrm{AD}$ & $\mathrm{C}_{21 /(\mathrm{AD})}$ & 0 & - & - & - & - & 1,212 \\
\hline \multirow{10}{*}{ 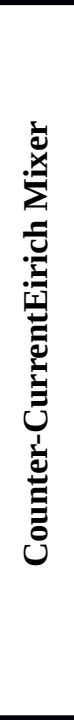 } & \multirow{3}{*}{$\begin{array}{c}\text { RCA/MDE- } \\
21\end{array}$} & $500 \mathrm{RPM}$ & $\mathrm{AD}$ & $>_{<-21 / 500(\mathrm{AD})}$ & 0 & 0,299 & 2,075 & 2,354 & 4,771 & 6,038 \\
\hline & & $300 \mathrm{RPM}$ & $\mathrm{AD}$ & $><21 / 300(\mathrm{AD})$ & 0 & 0,202 & 0,822 & 1,054 & 2,571 & 3,286 \\
\hline & & $150 \mathrm{RPM}$ & $\mathrm{AD}$ & $-><-21 / 150(\mathrm{AD})$ & 0 & - & - & - & - & 1,352 \\
\hline & $\begin{array}{c}\text { RCA/MDE- } \\
21\end{array}$ & $500 \mathrm{RPM}$ & SSD & $><21 / 500$ (SSD) & 0 & $-0,008$ & 1,704 & 2,368 & 4,783 & 6,461 \\
\hline & \multirow{3}{*}{$\begin{array}{c}\text { RCA/MDE- } \\
27\end{array}$} & $500 \mathrm{RPM}$ & SSD & $\left.\right|_{<-27 / 500(\mathrm{AD})}$ & 0 & 0,274 & 0,920 & 1,366 & 4,873 & 8,405 \\
\hline & & $300 \mathrm{RPM}$ & $\mathrm{AD}$ & $><-27 / 300(\mathrm{AD})$ & 0 & - & - & - & - & 3,926 \\
\hline & & $150 \mathrm{RPM}$ & $\mathrm{AD}$ & $><-27 / 150(\mathrm{AD})$ & 0 & - & - & - & - & 1,855 \\
\hline & \multirow{3}{*}{ NA / MDE-6 } & $500 \mathrm{RPM}$ & $\mathrm{AD}$ & $b_{<}<06 / 500(\mathrm{AD})$ & 0 & - & - & - & - & 1,923 \\
\hline & & $300 \mathrm{RPM}$ & $\mathrm{AD}$ & $>_{<-06 / 300(\mathrm{AD})}$ & 0 & - & - & - & - & 1,104 \\
\hline & & $150 \mathrm{RPM}$ & $\mathrm{AD}$ & $><-06 / 150(\mathrm{AD})$ & 0 & - & - & - & - & 0,401 \\
\hline \multirow{10}{*}{ 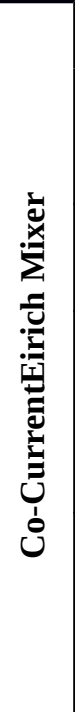 } & \multirow{3}{*}{$\begin{array}{c}\text { RCA/MDE- } \\
21\end{array}$} & $500 \mathrm{RPM}$ & $\mathrm{AD}$ & $\Rightarrow 21 / 500(\mathrm{AD})$ & 0 & 1,759 & 4,411 & 5,221 & 8,756 & 10,931 \\
\hline & & $300 \mathrm{RPM}$ & $\mathrm{AD}$ & $321 / 300(\mathrm{AD})$ & 0 & - & - & - & - & 3,053 \\
\hline & & $150 \mathrm{RPM}$ & $\mathrm{AD}$ & Z 21/150(AD) & 0 & - & - & - & - & 0,779 \\
\hline & $\begin{array}{c}\text { RCA/MDE- } \\
21\end{array}$ & $500 \mathrm{RPM}$ & SSD & \21/500(SSD) & 0 & 0,979 & 3,573 & 4,722 & 8,598 & 11,377 \\
\hline & \multirow{3}{*}{$\begin{array}{c}\text { RCA/MDE- } \\
27\end{array}$} & $500 \mathrm{RPM}$ & $\mathrm{AD}$ & $327 / 500(\mathrm{AD})$ & 0 & - & - & - & - & 12,420 \\
\hline & & $300 \mathrm{RPM}$ & $\mathrm{AD}$ & - $27 / 300(\mathrm{AD})$ & 0 & - & - & - & - & 5,452 \\
\hline & & $150 \mathrm{RPM}$ & $\mathrm{AD}$ & \ 27/150(AD) & 0 & - & - & - & - & 0,994 \\
\hline & \multirow{3}{*}{ NA / MDE-6 } & $500 \mathrm{RPM}$ & $\mathrm{AD}$ & 6/ 500 (AD) & 0 & - & - & - & - & 3,673 \\
\hline & & $300 \mathrm{RPM}$ & $\mathrm{AD}$ & 6/ 300 (AD) & 0 & - & - & - & - & 0,726 \\
\hline & & $150 \mathrm{RPM}$ & $\mathrm{AD}$ & 6/ 150 (AD) & 0 & - & - & - & - & 0,1 \\
\hline
\end{tabular}

